\title{
Discussion on the Teaching Management of Apprentices with "Dual-Identity" Based on the School-Enterprise Co-Construction*
}

\author{
Jiancui Ma \\ Hunan Modern Logistics College \\ Changsha, China
}

\author{
Jing Zhong** \\ Hunan Modern Logistics College \\ Changsha, China \\ **Corresponding Author
}

\begin{abstract}
At present, in the process of cultivating higher vocational students, in order to closely connect with the market and cultivate skilled talents that meet market demand, universities have made various attempts in the talent training model. School-enterprise co-construction is one of them. The current forms of school-enterprise co-construction include "titled (order) classes" and "titled colleges". This article defines the talent training of "dual-identity" apprentices based on the school-enterprise co-construction background. Based on the differences between the characteristics of current schoolenterprise co-construction students and ordinary students, this paper explores the apprenticeship training model based on "dual-identity" and the teaching management model.
\end{abstract}

Keywords-school-enterprise co-construction; dual-identity; apprentice; teaching management

\section{INTRODUCTION}

The apprenticeship teaching management mode is the mode in which vocational colleges use school-enterprise coconstruction for talent co-cultivation. In this talent training process, students change from a single student status to a dual status of school students and corporate employees. The supervision and evaluation of students are completed under the constraints of the dual system of schools and enterprises. The specifications and requirements for talent training are the goals of talent training jointly formulated by the school and the enterprise according to the needs of the industry market. The process of teaching management begins with the formulation of talent training programs, with the joint participation of schools and enterprises, joint development, joint training, and joint assessment. Dual-subject and dualidentity are the characteristics of apprenticeship training.

\section{The MEANING OF "DUAL-IDENTITY” APPRENTICESHIP TRAINING}

At present, schools and enterprises jointly carry out modern apprenticeship trials in the form of "title (order) class", production-education integration, "named college"

*Fund: School-level project - study on the teaching management and evaluation mechanism of "dual-identity" apprentices in the context of modern apprenticeship, XM8457574366E55D14. and other forms. Among them, the development of a "double-identity" modern apprenticeship talent training based on the "double subject" co-construction of a secondlevel college is the most closely-trained model of talent training. In this training mode, modern apprentices have dual status as "school students" and "enterprise apprentices", and are trained and managed by the "dual subjects" of "schools" and "enterprises". Establishing an effective "modern apprentice" management mechanism is the key to the smooth development of this talent training model. It is also the key to achieve the orderly operation of the talent training of the "double-subject" secondary colleges in schools and enterprises and ensuring the quality improvement of "dualidentity" modern apprenticeships.

The teaching management process of "double-identity" talent training is completed by the school mentor and the enterprise mentor. There are two places for students to learn, such as learning and business. Theoretical study, on-campus practice and business practice constitute the main learning modules for students. The school's faculty and corporate faculty together form an apprenticeship teaching team. The school system and the enterprise system are merged to form the supervision system for apprentice students. School incentives and corporate incentive systems are related systems that apprentices should follow together. Evaluation of apprenticeship is also completed by the relevant regulations of the school and the relevant systems of the enterprise. Apprentices are constrained by dual-subject (schools and businesses) and assume double-identity responsibilities (students and employees).

\section{THE CHARACTERISTICS OF MODERN APPRENTICES AND THE ANALYSIS OF COMPARISON WITH ORDINARY STUDENTS' TEACHING MANAGEMENT AND EVALUATION \\ A. The Characteristics of Modern Apprentices}

China has a tradition of training apprentices since ancient times. The traditional apprenticeship is cultivated in the form of a help belt. The apprentice calls his teacher majstro. At present, with the development of society and the support for technology being re-emphasized, vocational education has developed rapidly. In the development process, in order to 
apprenticeships and ordinary students' teaching management and evaluation systems. vocational education has adopted various talent training models for the cultivation of vocational and technical talents. Apprenticeship is a model for talent training. Vocational education apprenticeships are different from traditional apprenticeships. Students take the school as the center and adopt the form of school theoretical learning and business practice to complete the cultivation of technical ability. Their learning process is to learn the professional knowledge and enter the company for an internship, so they have a preliminary understanding of the profession and the industry. Then after one year of professional knowledge study, followup internships and follow-up internships for various positions in the industry will be provided to deepen the understanding and cognition of professional knowledge. Finally, through the post internship, students complete the mastery of professional post technology. The current object of apprentice training is the existence of a "dual identity", that is, the dual identity of school students and corporate employees. The learning process is an intertwined process of these two identities, and is a process jointly cultivated by the school mentor and the enterprise mentor.

The management of dual-identity apprenticeship students is mainly to guide students to the ultimate goal of selfmanagement in order to realize the value of their own lives. Incorporate the standards of both the school and the enterprise in the incentive and competition mechanisms to help students establish a correct view of learning and build and consolidate self-confidence. At the same time, it is necessary to fully refer to the actual situation of the students, focus on the future development of the students, help the students to set reasonable goals, and adopt corresponding incentives from the three aspects of work, results and education and training. At the same time, in the management of students, both sides must use reasonable competition mechanisms to achieve better means and methods for the survival of the fittest.

\section{B. Comparison of Talent Training Between Modern Apprentices and Teaching Management and Evaluation of Ordinary Students}

Talent training for modern apprentices is done jointly by schools and companies. The training of ordinary students is done unilaterally by the school. The management of modern apprenticeships is subject to the supervision and management of both the school and the enterprise. The evaluation system is the combination of different evaluation systems given by the school and the enterprise during the non-learning phase to make the final evaluation result. The evaluation content includes the school's performance and the skills and professionalism of the company's internship. Students are identified as students during school, subject to the evaluation system of the school, and as employees of the company during the internship of the enterprise, and subject to the evaluation system of the enterprise. The evaluation system for ordinary students only includes the school evaluation system. Dual identities, dual constraints and dual evaluations are the differences between modern

\section{DiscusSION ON THE APPRENTICE TRAINING MODEL BASED ON "DUAL-IDENTITY" (CORPORATE EMPLOYEE PLUS SCHOOL STUDENT)}

"Dual-identity" apprenticeship training for enterprise employees + school students is a learning process jointly completed by the school and the enterprise. Starting from the choice of enterprises for school-enterprise cooperation training, schools should be positioned on a win-win model of school-enterprise cooperation for resource sharing and talent sharing. From the formulation of talent training, teaching methods, internship training, and student assessments, both the school and the enterprise should be involved to develop a more reasonable and more motivating mechanism.

\section{A. School-Enterprise Win-Win Cooperation and Resource Sharing}

The current model of apprenticeship has changed from the traditional model. Student learning is still centered on the school, but as an apprentice, the nature of the apprenticeship basically exists. The student also needs to master the work skills of the enterprise, and can be employed directly after life. Talent training is seamlessly connected with employment positions, and the school has achieved the expected goals in terms of talent training. For the enterprise, the talents needed by the enterprise are reasonably resolved, and both sides of talent training are win-win. However, in terms of the current new model of talent training, to achieve the expected goals, companies and schools need to share resources in talent training, jointly build internships and training, and implement "student + staff" dual evaluation and motivation.

Training qualified apprentices is the common goal of schools and businesses. Enterprises should provide students with opportunities for internship practice and a teacher training base. The school-enterprise co-construction or enterprise follow-up can be adopted to meet students' practical learning and teacher training needs. Enterprise work case resources are shared with the school to meet the use of teaching classroom resources and achieve the desired effect of teaching.

\section{B. School Collaborates with Enterprise to Formulate a Reasonable Talent Training Plan}

The development of the talent training plan is jointly completed by the school mentor and the enterprise mentor after analyzing the current industry situation, industry job skills, and industry development trends. It not only covers the basic theoretical knowledge of the professional field, but also includes the training of post talents. It can also meet the needs of knowledge development in the field of industry development and the needs of students' career development. Talent training is based on the present and the future, and has achieved effective docking of talent training, corporate benefits and social services. 
work is required to be completed after class in theoretical study and practice places. The school uses this as part of the curriculum assessment. Student assessment and motivation are implemented by both the school and the enterprise. Not only can you enjoy the various reward systems of the school, but the company also has a special scholarship system. The two sides formulated the evaluation mechanism based on the criteria of enterprise assessment, in this way, students can understand the corporate culture faster and better, and accept the corporate culture.

\section{B. The Teaching Management Model of "Dual-Identity" Apprentices for Employee Status}

The employee status of the "dual-identity" apprentice is the student's identity during the company's follow-up and post-employment practice. At this time, the students are completely in the working environment of the enterprise, and the management of the students is carried out strictly in accordance with the management mode of the enterprise employees. The assessment method is the same as that of the intern employees in the same position in the enterprise. The company conducts regular job training for apprentice employees to master the basic skills of the job. Enterprises provide them with career planning training, allowing them to complete basic job literacy and training of career development elements in the enterprise.

At the same time, the employee status of "dual-identity" apprentices is also subject to the supervision and management of the school. The school mentors regularly go into the enterprise to discuss the post practice process with students, guide the students' psychological and professional issues in time, and guide them to steadily change from student status to employee status. At the same time, according to the performance of apprentice employees in the company, the teacher approves the corresponding practical credits and urges them to complete their studies.

\section{CONCLUSION}

The teaching management of "dual-identity" apprentices in the context of school-enterprise cooperation is a kind of teaching management model that is closer to the talent training of enterprises and seamlessly connects with enterprises. Students changed the traditional single mode of accepting theoretical knowledge learning, combining theoretical learning with mastery of post skills. Knowledge learning and job vocational quality are carried out at the same time, and apprentices are jointly trained and supervised by school mentors and business mentors. Teachers are jointly constructed by schools and enterprises. Its training objectives are to achieve: first, students are required to master theoretical and practical skills and professional literacy within the time of the academic system; second, students can quickly integrate into the enterprise after graduation; third, they can directly dock positions and master the skills of the positions; fourth, they can adapt to the various cultures of the enterprise and complete the transformation of students into corporate employees. arrangements during their student status, theoretical assessments follow the requirements of talent training, classroom management is strictly in accordance with the $6 \mathrm{~s}$ management model of the enterprise, and venue restoration 


\section{REFERENCES}

[1] Zhang Yan. Research on the Innovative Model of Talent Training in Senior Technical School Based on the New Apprenticeship System of Enterprises [J]. Think Tank Era, 2019, 10. (in Chinese)

[2] Chen Xiaoping. Research on Jinhua City's Advanced Talent Cultivation Operating Mechanism under the Apprenticeship Model Taking Manufacturing Talents as Examples [J]. China Journal of Commerce, 2019, 10. (in Chinese)

[3] Yu Bin. Construction of Modern Apprentice Talent Training System for Finance Major in Higher Vocational Colleges [J]. China Market, 2019, 10. (in Chinese) 